\title{
DEVELOPMENT OF A CORRELATION FOR EVALUATING THE CIGARETTE FIRMNESS FOR PRODUCTION QUALITY CONTROL
}

\begin{abstract}
F. G. Nogueira ${ }^{a}$ ABSTRACT
and A. F. Orlando

${ }^{a}$ Quality Control Manager

Estrada do Guerenguê 1421

CEP. 22713-001, Rio de Janeiro, Brazil

francy.goersch@oi.com.br

${ }^{\mathrm{b}} \mathrm{LAME}$

Pontifical Catholic University of Rio de Janeiro Mechanical Engineering Department Rua Marquês de São Vicente 225 CEP. 22453-900, Rio de Janeiro, Brazil

Cigarette quality can be monitored in the market by evaluating its degree of rigidity, which is defined as the ratio of the final cigarette diameter, following a compression test, to its initial diameter, and is usually called cigarette firmness. Aiming the comparison between several products, the measured firmness is corrected to a previously specified reference moisture value by means of an exponential model, as validated and accepted by cigarette manufacturers. Following already qualified procedures, the firmness of eleven cigarette brands were measured in this work as a function of upright deformation, as produced by applying a standard load, mean circumference and specified tobacco moisture. The method of minimum squares was used for generating several correlations, together with the uncertainty evaluation, in order to achieve the one that could result in the lowest uncertainties, not estimated yet. The conclusion is that the tobacco characteristics are the largest contribution to the uncertainty of firmness measurement, resulting in a poor repeatability. On the basis of these results, it is suggested that a product acceptance criteria in the production line be established on the basis of the measurement uncertainties, using for reference the firmness value ranges usually accepted and tested by the market.
\end{abstract}

Keywords: metrology; cigarettes; firmness; uncertainty

\section{NOMENCLATURE}

C circumference

$\bar{C} \quad$ average circumference

$E \quad$ normalized error

$F \quad$ firmness

$\mathrm{H} \quad$ moisture content

$L \quad$ dimension of cigarette

$\mathrm{P}_{1} \quad$ mass of empty can

$\mathrm{P}_{2} \quad$ mass of can filled with humid tobacco

$\mathrm{P}_{3} \quad$ mass of humid tobacco

$\mathrm{P}_{4} \quad$ mass of can filled with dry tobacco

$\mathrm{P}_{5} \quad$ mass of dry tobacco

$\mathrm{P}_{6} \quad$ mass of water and volatile products

$\mathrm{RH}$ relative humidity

$\mathrm{U}$ expanded uncertainty

$X \quad$ normalized moisture content

$\bar{X}$

$\mathrm{d}$

$\bar{d}$

e

$\mathrm{g}$

$\mathrm{mm}$

$p$

$\mathrm{t}$

$y$ average value

diameter

average diameter

correction

gram

millimeter

number of constants that should be determined in the fitting

t-student coefficient

normalized firmness

\section{Greek symbols \\ $u \quad$ standard uncertainty \\ $\sigma \quad$ data dispersion}

\section{Subscripts}

cor corrected

$\max \quad$ maximum

min minimum

p number of constants that should be determined in the fitting

fit fitting

target target value

tol tolerance

ET Station

$r \quad$ repeatability

d diameter

\section{INTRODUCTION}

The cigarette quality can be evaluated by means of several chemical and physical parameters. The chemical parameters are responsible for identifying and quantifying the tobacco components and the cigarette smoke. The physical parameters characterize the cigarette dimensions (length and circumference), mass, moisture, paper permeability, pressure drop, side loss, ventilation and firmness. Their measured values can be used to calculate 
quality indices, being used to monitor the product performance in the market.

Firmness is the rigidity of the cigarette, and relates the final to the initial diameter of the cigarette after a compression test, where a standard load is applied to the cigarette. The produced strain is a function of three variables: cigarette upright deformation; tobacco moisture, and cigarette mean circumference. Former studies indicate that moisture is the parameter that mostly influences the cigarette firmness. When comparing the performance of several cigarettes, the measured firmness must be corrected to a standard moisture value, which characterizes the commercial product. A standard ISO 3402 (1999) in this work was followed for conditioning the product at $(60 \pm 3) \%$ Relative Humidity $(\mathrm{RH})$ and $(22 \pm 1){ }^{\circ} \mathrm{C}$ temperature for a 48 $\mathrm{h}$ period before introducing it into the market. For process control, however, it is not possible to interrupt the production and store a sample for $48 \mathrm{~h}$. A mathematical model must be used to estimate the firmness that could be obtained if the test was performed at the standard conditions.

The objective of this paper is to validate the experimental procedure used to generate data in Nogueira (2005), to estimate the uncertainty of the results, with $95.45 \%$ confidence level, and to metrologically evaluate correlations between cigarette firmness and cigarette parameters, analyzing their influence in the production quality control.

\section{MEASUREMENT EQUIPMENTS}

\section{Firmness measurement}

Two BORGWALDT firmness stations, respectively D-37 and DD-60A models, were used to measure the cigarette firmness. A standard force is applied to the sample during a given time interval, resulting in its deformation along the vertical direction. Ten cigarettes are placed horizontally side by side between two parallel plates. A standard load is applied over the upper plate, thus compressing the sample. The vertical displacement of the upper plate is thus measured, thus defining the final average cigarette upright dimension, which is divided by the cigarette initial diameter to give a percent value for its firmness.

\section{Circumference measurement}

A CTS circumference station, manufactured by CERULEAN/FILTRONA, and a SODIMAT circumference station, manufactured by SODIM Instrumentation, was used to measure the average cigarette circumference, besides cigarette mass, pressure drop and ventilation, which do not influence directly the firmness measurement.

In the SODIMAT circumference station, the cigarettes are placed inside a test chamber, where each one is rotated. The mean cigarette circumference is measured 1024 times by a laser beam, as the cigarette makes a complete turn; with a resolution of
$0.0025 \mathrm{~mm}$. Average values and standard deviation are calculated. In the CTS circumference station, about 100 circumference measurements are performed in each cigarette, with a resolution of 0.01 $\mathrm{mm}$, and repeatability of $0.05 \mathrm{~mm}$.

Stainless steel circular cylinders are measured by a Laboratory accredited by the Brazilian Calibration Network, and used to calibrate the circumference stations.

\section{Tobacco moisture measurement}

An oven, manufactured by G.H. Bowen, was used to measure the tobacco moisture content, defined as the ratio between the amount of volatile compounds in the tobacco sample and its mass (expressed in \%). Air, heated by an electric resistance, after having its temperature homogenized by a fan, is blown through five vertically packed trays, each one containing twenty cans filled with tobacco to be dried out. It is then released to the atmosphere, carrying the volatile compounds, mainly moisture, which is measured by weighting the samples before and after the test.

\section{Tobacco conditioning}

The laboratory of this research has a conditioning room, where the dried tobacco samples are stored before going the next test. Its temperature is kept to within $(22 \pm 1){ }^{\circ} \mathrm{C}$. Its humidity, to within $(60 \pm 3) \%$, according to standard ISO 3402 (1999). However, another chamber, manufactured by Binder $\mathrm{GmbH}$, with a setting temperature resolution of \pm 0.1 ${ }^{\circ} \mathrm{C}$, and setting humidity resolution of $\pm 1 \% \mathrm{RH}$, was used in these test to measure the time required for the tobacco samples to achieve equilibrium conditions.

\section{VALIDATION OF THE MEASUREMENT PROCEDURE}

\section{Time required for conditioning tobacco samples}

As a first step to qualify the measurement procedure, twelve sets of ten cigarettes, each, were placed in the conditioning chamber. The same amount of cigarettes was placed in the conditioning room. The same initial conditions were set for experiments, $(22 \pm 1){ }^{\circ} \mathrm{C}$ for temperature, and $(60 \pm$ 3) $\%$ for RH. The tobacco was weighted every $2 \mathrm{~h}$ over a three day period.

The objective of the tests was to evaluate the influence of the conditioning time on the moisture content of the sample, and also to compare the conditioning process for both conditioning chamber and room, including the influence of the sample position on the moisture absorption by tobacco. The tests were used to determine when there is no more moisture absorption by the tobacco, meaning that the samples are fully conditioned to the required temperature and $\mathrm{RH}$ conditions. 


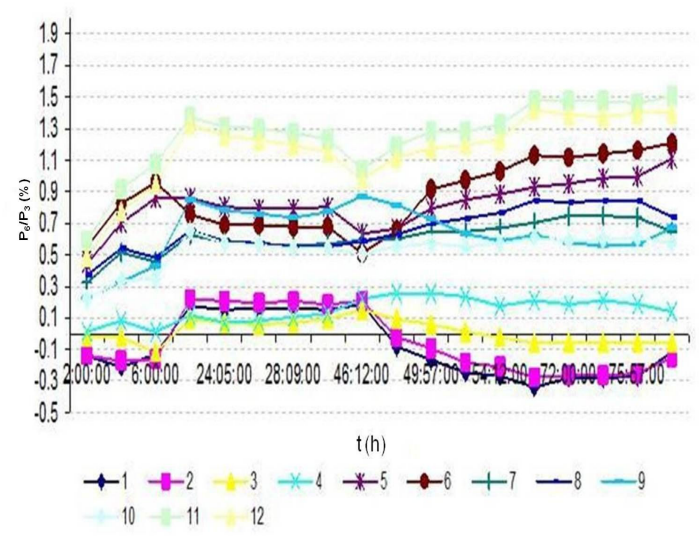

Figure1. Percentage mass variation in conditioning chamber.

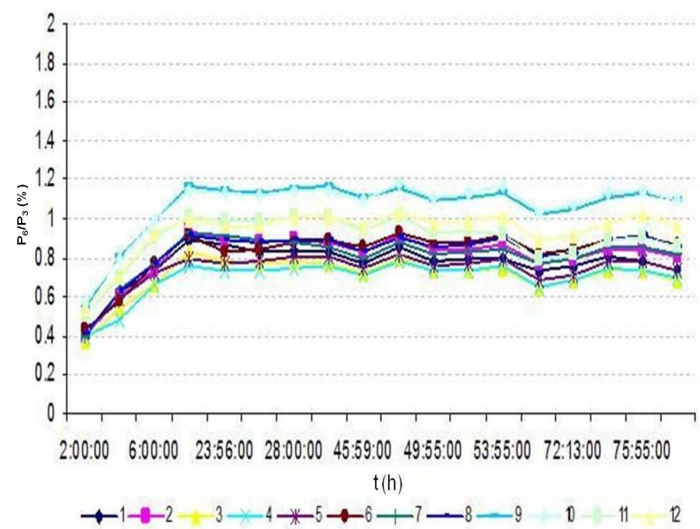

Figure 2. Percentage mass variation in the conditioning room.

Figure 1 shows the absorption of moisture as a function of time for each one of the twelve trays placed in the conditioning chamber. It is shown that there is a trend towards absorbing more moisture in the upper trays, and that the central trays achieve quicker the equilibrium conditions.

Figure 2 shows that the stability in the conditioning room is higher than in the conditioning chamber. Even though, for operational reasons, it was decided to make the experiments in the conditioning chamber. Thus, it was decided to condition the tobacco in later tests for a period between 24 and 30 $\mathrm{h}$, because the mass variation is less than $0.2 \%$, which meets the ISO 3402 (1999) criteria for sample conditioning that also suggests a $48 \mathrm{~h}$ conditioning time interval.

Tobacco moisture content after conditioning

The influence of the conditioning time of the sample on the tobacco moisture content was examined using six samples containing six sets of 20 cigarettes, each one. Three samples were conditioned in the conditioning chamber for $24 \mathrm{~h}$ at, respectively, $(75 \pm 3) \%,(60 \pm 3) \%$ and $(40 \pm 3) \% \mathrm{RH}$ and $(22 \pm$ 1) ${ }^{\circ} \mathrm{C}$ temperature. Another three samples were conditioned for $48 \mathrm{~h}$, under similar temperature and
RH conditions. No significant differences were found in the 40 to $75 \% \mathrm{RH}$ range.

\section{Tobacco moisture content measurement}

Influence of sample mass on moisture content measurement.

Several experiments were conducted to determine the influence of the sample mass on the tobacco moisture content measurement. One hundred cans filled with tobacco were placed in an oven, each one having previously specified a nominal tobacco mass of 8,10 or $12 \mathrm{~g}$. The following parameters were measured for each can.

Table 1. Measured parameters for moisture determination.

\begin{tabular}{|c|c|l|}
\hline Symbol & Unit & \multicolumn{1}{|c|}{ Parameter } \\
\hline $\mathrm{P}_{1}$ & $\mathrm{~g}$ & Mass of empty can \\
\hline $\mathrm{P}_{2}$ & $\mathrm{~g}$ & $\begin{array}{l}\text { Mass of can filled with } \\
\text { humid tobacco }\end{array}$ \\
\hline $\mathrm{P}_{3}$ & $\mathrm{~g}$ & Mass of humid tobacco \\
\hline $\mathrm{P}_{4}$ & $\mathrm{~g}$ & $\begin{array}{l}\text { Mass of can filled with } \\
\text { dry tobacco }\end{array}$ \\
\hline $\mathrm{P}_{5}$ & $\mathrm{~g}$ & Mass of dry tobacco \\
\hline $\mathrm{P}_{6}$ & $\mathrm{~g}$ & $\begin{array}{l}\text { Mass of water and } \\
\text { volatile products }\end{array}$ \\
\hline
\end{tabular}

The mass of water and volatile products $\left(P_{6}\right)$ can be calculated as:

$$
P_{6}=P_{3}-P_{5}=\left(P_{2}-P_{1}\right)-\left(P_{4}-P_{1}\right)
$$

Considering that the tobacco moisture content is not the same for each of $n$ cans, together with the non uniformity of the drying process, an average value $(\bar{X})$ must be calculated using the mass of water and volatile products for each can $\left(X_{i}\right)$, calculated from Eq. (1). Also, the standard uncertainty $(u)$, according to ISO GUM (1995) can be calculated as its standard deviation, because the uncertainty of mass measurement is much smaller than the data dispersion due to non uniformity.

$$
\begin{gathered}
\bar{X}=\frac{1}{n} \cdot \sum_{i=1}^{n} X_{i} \\
u=\sqrt{\frac{1}{n-1} \cdot \sum_{i=1}^{n}\left(X_{i}-\bar{X}\right)^{2}} \\
U=t * u
\end{gathered}
$$

Using as a definition of the tobacco moisture content $(H)$ the percent ratio between the mass of water and volatile products $\left(P_{6}\right)$ and the mass of humid tobacco $\left(P_{3}\right)$. Table 2 shows the measured values considering that each can has a nominal 
tobacco mass of 8,10 and $12 \mathrm{~g}$, after having dried the samples in an oven for $3.5 \mathrm{~h}$ at $110{ }^{\circ} \mathrm{C}$.

Table 2. Tobacco moisture content after having been dried for $3.5 \mathrm{~h}$ at $110^{\circ} \mathrm{C}$.

\begin{tabular}{|c|c|c|c|c|}
\hline 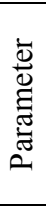 & $\begin{array}{c}\text { Nominal } \\
\text { tobacco } \\
\text { mass } \\
\mathrm{g}\end{array}$ & $\begin{array}{c}\text { Humid } \\
\text { tobacco } \\
\mathrm{g}\end{array}$ & $\begin{array}{c}\text { Water } \\
\text { and } \\
\text { volatile } \\
\text { products } \\
\text { g }\end{array}$ & $\begin{array}{c}\text { Tobacco } \\
\text { moisture } \\
\text { content } \\
\%\end{array}$ \\
\hline $\bar{X}$ & \multirow{2}{*}{8} & 8.0000 & 1.1230 & 14.0380 \\
\hline$u$ & & 0.0007 & 0.0049 & 0.0610 \\
\hline $\bar{X}$ & \multirow{2}{*}{10} & 10.0000 & 1.3970 & 13.9720 \\
\hline$u$ & & 0.0007 & 0.0101 & 0.1011 \\
\hline $\bar{X}$ & \multirow{2}{*}{12} & 12.0000 & 1.6710 & 13.9260 \\
\hline$u$ & & 0.0006 & 0.0091 & 0.0751 \\
\hline
\end{tabular}

Table 2 indicates that to within the uncertainty of measurement the measured tobacco moisture content does not depend on humid tobacco mass to be dried. Thus, an average value for the tobacco content can be calculated using all the measured values, independently of the humid tobacco mass to be dried. Using Eq. (4), the expanded uncertainty can be calculated for $95.45 \%$ confidence level.

$$
H=(13.98 \pm 0.18) \%
$$

Influence of the drying time in the oven and use of a dehumidifier to complement the tobacco drying.

A similar experiment was conducted with 99 cans filled with tobacco to be dried during a $3 \mathrm{~h}$ time interval in an oven at $110{ }^{\circ} \mathrm{C}$. Then, a dehumidifier was used to complement the drying process until the samples achieved a temperature of $50{ }^{\circ} \mathrm{C}$, as suggested by a used methodology. The tobacco moisture content was slightly reduced and the uncertainty slightly increased.

$$
H=(13.15 \pm 0.25) \%
$$

The use of the normalized error $(E)$ statistical test in Orlando (2009) for comparing the two values (zero average statistical tests) resulted in a value of 2.7. This value is well above $1(95.45 \%$ confidence level), indicating that the two procedures are different and systematic errors may be occurring. Possibly the samples are not completely dried in the last test.

$$
E=\frac{13.98-13.15}{\sqrt{0.8^{2}+0.25^{2}}}=2.7
$$

Influence of drying temperature on tobacco moisture content measurement.
Three experiments were conducted, each one with 20 cans filled with tobacco, in the oven temperature range around the set point of $(110 \pm 1)$ ${ }^{\circ} \mathrm{C}$, during a $3.5 \mathrm{~h}$ time interval, simulating a drift in the set point.

Table 3 shows that there is a trend towards determining a larger tobacco moisture content when the temperature increases. However, when comparing the results at $109^{\circ} \mathrm{C}$ and $111^{\circ} \mathrm{C}$, the normalized error is equal to 0.99 , meaning that the results are still statistically meaningful (less than 1). Physically, this difference indicates that the tobacco is not completely dry at lower temperatures and needs to be in the oven during a larger time interval.

$$
E=\frac{11.95-11.74}{\sqrt{0.15^{2}+0.15^{2}}}=0.99
$$

Table 3. Tobacco moisture content determination at different oven temperatures.

\begin{tabular}{|c|c|c|}
\hline $\begin{array}{c}\text { Oven } \\
\text { temperature } \\
{ }^{\circ} \mathrm{C}\end{array}$ & $\bar{X}$ & $U$ \\
\hline 109 & 11.74 & 0.15 \\
\hline 110 & 11.82 & 0.14 \\
\hline 111 & 11.95 & 0.15 \\
\hline
\end{tabular}

Influence of the amount of tobacco in the oven on its moisture content determination.

Keeping the oven temperature $\left(110{ }^{\circ} \mathrm{C}\right)$ and drying time $(3.5 \mathrm{~h})$ as constants, the influence of the amount of tobacco in the oven on the moisture content determination was investigated, by emptying some of the 100 cans placed inside the oven. Five experiments were conducted, respectively, for 20, 25, 50, 75 and 100 cans filled with tobacco.

Table 4 indicates that all differences are smaller than the uncertainty of measurement, which means that the amount of tobacco in the oven does not seem to be important for tobacco moisture content determination. The normalized error between any two configurations is much smaller than 1 , meaning that the results are statistically meaningful.

Influence of drying time in the oven on the tobacco moisture content determination.

The drying time of the tobacco in the oven was varied from 1 to $7 \mathrm{~h}$ to check its influence on the tobacco moisture content determination. It can be concluded from Table 5 that the tobacco needs to stay longer than $3.5 \mathrm{~h}$ in the oven to be completely dry and the systematic errors be reduced. As a conclusion, it was assumed that the uncertainty of measuring the tobacco moisture content is $\pm 0.29 \%$. 
Table 4. Influence of the amount of tobacco in the oven on its moisture content determination $(\bar{X})$.

\begin{tabular}{|c|c|c|}
\hline $\begin{array}{c}\text { Number of cans } \\
\text { filled with tobacco } \\
{ }^{\circ} \mathrm{C}\end{array}$ & $\bar{X}$ & $U$ \\
\hline 20 & 12.87 & 0.24 \\
\hline 25 & 12.90 & 0.29 \\
\hline 50 & 12.80 & 0.26 \\
\hline 75 & 12.76 & 0.29 \\
\hline 100 & 12.87 & 0.24 \\
\hline
\end{tabular}

Table 5. Influence of drying time in the oven on the tobacco moisture content determination $(\bar{X})$.

\begin{tabular}{|c|c|c|}
\hline $\begin{array}{c}\text { Drying } \\
\text { time } \\
\mathrm{h}\end{array}$ & $\bar{X}$ & $U$ \\
\hline 1.0 & 10.93 & 0.79 \\
\hline 1.5 & 11.95 & 0.45 \\
\hline 2.0 & 12.50 & 0.30 \\
\hline 2.5 & 12.92 & 0.28 \\
\hline 3.0 & 13.15 & 0.31 \\
\hline 3.5 & 13.38 & 0.22 \\
\hline 4.0 & 13.61 & 0.24 \\
\hline 5.0 & 13.89 & 0.26 \\
\hline 6.0 & 14.16 & 0.24 \\
\hline 7.0 & 14.32 & 0.31 \\
\hline
\end{tabular}

Calibration of the stainless steel cylinders used as reference materials for calibrating the stations.

Seven stainless steel cylinders were manufactured in different diameters, ranging from 5 to $8 \mathrm{~mm}$, in $0.5 \mathrm{~mm}$ steps. Ten diameter measurements were made for each cylinder by a digital caliper, calibrated by a laboratory in the Brazilian Calibration Network to within $U_{p}= \pm 0.01$ $\mathrm{mm}(95.45 \%)$. The standard uncertainty is thus $u_{p}=$ $U_{\mathrm{p}} / 2=0.005 \mathrm{~mm}$. The average diameter $(\bar{d})$ was calculated using Eq. (2) and $n=10$. The standard deviation $\left(u_{r}\right)$ was calculated using Eq. (3) and $n=10$. Thus the combined uncertainty $\left(u_{d}\right)$ can be calculated by Eq. (9). The expanded uncertainty $\left(U_{d}\right)$ can be calculated using Eq. (4), with $\mathrm{t}=2.32$ (9 degrees of freedom). Average circumference ( $\bar{C}$ ) and expanded uncertainty $\left(U_{C}\right)$ are calculated using, respectively, Eq. (10) and Eq. (11).

$$
\begin{gathered}
u_{d}=\sqrt{u_{p}^{2}+u_{r}^{2}} \\
\bar{C}=\pi \cdot \bar{d} \\
U_{C}=\pi \cdot U_{d}
\end{gathered}
$$

Table 6 shows the results of the calibration of the CTS circumference station. Diameters were measured at the same position along the cylinder length that the CTS test station measures the cigarette diameter.

Table 6. Calibration of the stainless steel cylinders (CTS circumference station position).

\begin{tabular}{|c|c|c|c|c|c|c|}
\hline $\begin{array}{c}\text { Cylinder } \\
\text { nominal } \\
\text { diameter } \\
\text { mm }\end{array}$ & $u_{p}$ & $u_{r}$ & $u_{d}$ & $\bar{d}$ & $\bar{C}$ & $U_{C}$ \\
\hline 5.00 & 0.005 & 0.00000 & 0.005 & 4.990 & 15.677 & 0.036 \\
\hline 5.50 & 0.005 & 0.00000 & 0.005 & 5.500 & 17.279 & 0.036 \\
\hline 6.00 & 0.005 & 0.00000 & 0.005 & 6.000 & 18.850 & 0.036 \\
\hline 6.50 & 0.005 & 0.00000 & 0.005 & 6.500 & 20.420 & 0.036 \\
\hline 7.00 & 0.005 & 0.00000 & 0.005 & 7.000 & 21.991 & 0.036 \\
\hline 7.50 & 0.005 & 0.00000 & 0.005 & 7.500 & 23.562 & 0.036 \\
\hline 8.00 & 0.005 & 0.00516 & 0.007 & 8.014 & 25.177 & 0.052 \\
\hline
\end{tabular}

\section{Circumference measurement}

A CTS circumference station and a SODIMAT circumference station were used to measure the average cigarette circumference. They are calibrated using stainless steel cylinders, which are measured by the stations and thus calibrated for cigarette diameter measurement.
Similar measurements were made also at the same position along the cylinder length that the SODIMAT circumference station measures the cigarette diameter. The normalized error test shows that there is no statistical difference between the results. Even though, a different calibration curve was used for the SODIMAT circumference station position 
Table 7. Calibration of CTS circumference station.

\begin{tabular}{|c|c|c|c|c|c|c|c|}
\hline \multirow{2}{*}{ Parameter } & \multicolumn{7}{|c|}{ Cylinder nominal diameter $(\mathrm{mm})$} \\
\cline { 2 - 8 } & 5.00 & 5.50 & 6.00 & 6.50 & 7.00 & 7.50 & 8.00 \\
\hline$u_{C}$ & 0.018 & 0.018 & 0.018 & 0.018 & 0.018 & 0.018 & 0.026 \\
\hline$u_{l}$ & 0.00577 & 0.00577 & 0.00577 & 0.00577 & 0.00577 & 0.00577 & 0.00577 \\
\hline$u_{r}$ & 0.00707 & 0.00516 & 0.00667 & 0.00471 & 0.00316 & 0.00422 & 0.01059 \\
\hline $\mathrm{C}$ & 15.677 & 17.279 & 18.850 & 20.420 & 21.991 & 23.562 & 25.177 \\
\hline $\bar{C}$ & 15.715 & 17.286 & 18.860 & 20.420 & 22.011 & 23.558 & 25.147 \\
\hline $\mathrm{e}$ & -0.038 & -0.007 & -0.010 & 0.000 & -0.020 & 0.004 & 0.030 \\
\hline$u_{e}$ & 0.022 & 0.004 & 0.006 & 0.000 & 0.011 & 0.002 & 0.017 \\
\hline$u_{E T}$ & 0.030 & 0.020 & 0.021 & 0.020 & 0.023 & 0.020 & 0.034 \\
\hline$U_{E T}$ & 0.070 & 0.047 & 0.049 & 0.046 & 0.052 & 0.046 & 0.078 \\
\hline
\end{tabular}

Calibration of the circumference stations.

During the calibration for circumference measurement, seven stainless steel cylinders with different diameters, used as reference materials, were measured ten times, each one, by both test station and digital caliper. A correction (e) was calculated as the difference between the average values indicated by the test station $(\bar{C})$ and by the digital caliper $(\mathrm{C})$. However, it was assumed that no correction should be added to the indicated value by the test station. Therefore, this systematic error was considered as a type B one, with standard uncertainty $\left(u_{e}\right)$ expressed as:

$$
u_{e}=\frac{|e|}{\sqrt{3}}
$$

The combined uncertainty of measuring the circumference by the circumference station was estimated with the help of the following components:

- Standard uncertainty of measuring circumference by the digital caliper $\left(u_{C}\right)$, Table 6 and Table 7.

- Repeatability of measuring circumference by the circumference station $\left(u_{r}\right)$, using Eq. (3), and $n=10$.

- Standard uncertainty of reading the circumference by the circumference station $\left(\mathrm{u}_{1}\right)$, calculated as the ratio between the reading resolution of the circumference station and $\sqrt{3}$.

The combined uncertainty of measuring the circumference by the circumference station $\left(u_{E T}\right)$ can thus be calculated by Eq. (13) and Eq. (14), where $u_{\sigma}$ is the uncertainty component due to data dispersion, Orlando (2009).

$$
\begin{array}{r}
u_{\sigma}=\sqrt{u_{l}^{2}+u_{r}^{2}} \\
u_{E T}=\sqrt{u_{\sigma}^{2}+u_{e}^{2}+u_{C}^{2}}
\end{array}
$$

The expanded uncertainty $\left(U_{E T}\right)$ can be calculated using Eq. (4). Table 7 shows the results of the calibration of the CTS circumference station, using seven stainless steel cylinders with different diameters. The same procedure was used for the SODIMAT circumference station. The normalized error test shows that there is no statistical difference between the results. Even though, a different calibration curve was used for the SODIMAT circumference station.

Uncertainty of measurement of cigarette circumference using circumference stations.

The cigarette uniformity and repeatability of the measurement procedure was evaluated by substituting the stainless steel cylinders for three types of cigarettes (F, H and B), with different brands and diameters. Each of the ten cigarettes was measured six times in each test station, using the same methodology as before. Table 8 shows the cigarette diameter and circumference measurement with a digital caliper for each test station. Table 9 shows similar results as measured by each circumference station.

From Table 6 and Table 8 it can be concluded that the uncertainty of measuring the average circumference with a digital caliper is much smaller for the rigid cylinders than for the cigarette, probably due to non-rigidity of the cigarette, what makes the measurement pressure an important and non repeatable parameter. This fact justifies why, for the digital caliper, the measured circumference is smaller and data dispersion is larger. As a conclusion, it was assumed that the uncertainty of measurement of the cigarette circumference by the circumference station was equal to the largest value in Table 9, that is, \pm $0.25 \mathrm{~mm}$.

\section{Firmness measurement}

Calibration of the reference cylinders.

The calibration of the firmness stations was made using, as transfer reference materials, six 80 $\mathrm{mm}$ long stainless steel cylinders. Each cylinder diameter was measured along its axis by a coordinate measuring machine. An average diameter $(d)$ was calculated as the arithmetic mean between the maximum $\left(d_{\max }\right)$ and minimum $\left(d_{\min }\right)$ diameters. 
Table 8. Cigarette diameter measurement with a digital caliper ( $\mathrm{mm})$.

\begin{tabular}{|c|c|c|c|c|c|c|}
\hline \multirow{2}{*}{ Parameter } & \multicolumn{3}{|c|}{$\begin{array}{c}\text { CTS circumference } \\
\text { station }\end{array}$} & \multicolumn{3}{c|}{$\begin{array}{c}\text { SODIMAT } \\
\text { circumference station }\end{array}$} \\
\cline { 2 - 7 } & $\mathrm{F}$ & $\mathrm{H}$ & $\mathrm{B}$ & $\mathrm{F}$ & $\mathrm{H}$ & $\mathrm{B}$ \\
\hline$u_{p}$ & 0.005 & 0.005 & 0.005 & 0.005 & 0.005 & 0.005 \\
\hline$u_{r}$ & 0.163 & 0.144 & 0.067 & 0.109 & 0.106 & 0.102 \\
\hline$u_{d}$ & 0.163 & 0.144 & 0.068 & 0.109 & 0.106 & 0.102 \\
\hline $\bar{d}$ & 7.451 & 7.069 & 5.301 & 7.481 & 7.119 & 5.340 \\
\hline $\mathrm{C}$ & 23.41 & 22.21 & 16.65 & 23.50 & 22.36 & 16.78 \\
\hline$U_{C}$ & 1.04 & 0.92 & 0.43 & 0.70 & 0.68 & 0.65 \\
\hline
\end{tabular}

Table 9. Cigarette circumference measurement with the circumference stations ( $\mathrm{mm})$.

\begin{tabular}{|c|c|c|c|c|c|c|}
\hline \multirow{2}{*}{ Parameter } & \multicolumn{3}{|c|}{ CTS circumference station } & \multicolumn{3}{c|}{ SODIMAT circumference station } \\
\cline { 2 - 7 } & $\mathrm{F}$ & $\mathrm{H}$ & $\mathrm{B}$ & $\mathrm{F}$ & $\mathrm{H}$ & $\mathrm{B}$ \\
\hline $\mathrm{C}$ & 23.41 & 22.21 & 16.65 & 23.50 & 22.36 & 16.78 \\
\hline $\bar{C}$ & 24.30 & 22.94 & 17.03 & 24.28 & 23.00 & 16.98 \\
\hline $\mathrm{e}$ & -0.89 & -0.73 & -0.37 & -0.77 & -0.63 & -0.20 \\
\hline$u_{l}$ & 0.00577 & 0.00577 & 0.00577 & 0.00577 & 0.00577 & 0.00577 \\
\hline$u_{r}$ & 0.059 & 0.056 & 0.098 & 0.094 & 0.065 & 0.122 \\
\hline$u_{\sigma}$ & 0.059 & 0.056 & 0.098 & 0.094 & 0.065 & 0.122 \\
\hline$U_{\sigma}$ & 0.12 & 0.12 & 0.20 & 0.19 & 0.13 & 0.25 \\
\hline
\end{tabular}

Table 10. Calibration of the reference cylinders $(\mathrm{mm})$ for firmness measurement.

\begin{tabular}{|c|c|c|c|c|c|c|}
\hline \multirow{2}{*}{ Parameter } & \multicolumn{7}{|c|}{$\begin{array}{c}\text { Reference cylinder } \\
\text { mm }\end{array}$} \\
\cline { 2 - 7 } & $\mathrm{A}$ & $\mathrm{B}$ & $\mathrm{C}$ & $\mathrm{D}$ & $\mathrm{E}$ & $\mathrm{F}$ \\
\hline$d$ & 7.9934 & 7.9940 & 6.000 & 6.003 & 4.003 & 4.002 \\
\hline$u_{\max }$ & 0.0022 & 0.0020 & 0.0015 & 0.0015 & 0.0015 & 0.0015 \\
\hline$u_{h}$ & 0.0003 & 0.0005 & 0.0000 & 0.0003 & 0.0000 & 0.0000 \\
\hline$u_{d}$ & 0.0022 & 0.0021 & 0.0015 & 0.0015 & 0.0015 & 0.0015 \\
\hline$U_{d}$ & 0.0044 & 0.0042 & 0.0030 & 0.0030 & 0.0030 & 0.0030 \\
\hline
\end{tabular}

The type A uncertainty of diameter measurement was selected as the maximum value $\left(U_{\max }\right)$ among those in the calibration certificate for different diameters along the cylinder axis. The diameter uniformity $\left(U_{h}\right)$ was defined as a type B uncertainty and calculated as the half the difference between the maximum $\left(d_{\max }\right)$ and minimum $\left(d_{\min }\right)$ diameters. Thus, the combined $\left(u_{d}\right)$ and the expanded $\left(U_{d}\right)$ uncertainties for the cylinder diameter can be expressed in Orlando (2009) by, respectively, Eq. (15) and Eq. (16) and shown in Table 10.

$$
\begin{aligned}
& u_{d}=\sqrt{u_{\text {max }}^{2}+u_{h}^{2}} \\
& U_{d}=2 * u_{d}
\end{aligned}
$$

Uncertainty of vertical displacement measurement using the reference cylinders.

Using the same methodology for calibrating the circumference stations, the D-37 and DD-60A Borgwaldt firmness stations were calibrated with the reference cylinders, indicating that the uncertainty of the final cigarette diameter after the compression test is in the \pm 0.014 to $\pm 0.021 \mathrm{~mm}$ range.
Thus, a value of $\pm 0.021 \mathrm{~mm}$ was assumed for the uncertainty of final cigarette diameter, with is approximately twice its resolution. In Eq. (2) is used to calculate the average value of the measured diameter by the firmness meter $(\bar{d})$, using reference cylinders $\mathrm{A}, \mathrm{B}, \mathrm{C}, \mathrm{D}, \mathrm{E}$ and $\mathrm{F}$ with diameter $d$ and its combined uncertainty $\left(u_{d}\right)$, given in Table 10 . The combined uncertainty of the final cigarette diameter $\left(u_{F}\right)$ is given by Eq. (1), together with its expanded uncertainty $\left(\mathrm{U}_{\mathrm{F}}\right)$, calculated by Eq. (4).

$$
u_{F}=\sqrt{u_{l}^{2}+u_{r}^{2}+u_{e}^{2}+u_{d}^{2}}
$$

Firmness measurement.

Firmness is the rigidity of the cigarette, and relates the final $(L)$ to the initial diameter $(d=C / \pi)$ of the cigarette, with circumference $C$, after a compression test, where a standard load is applied to the cigarette. Therefore, the indicated firmness value $(F)$ at the test conditions can be calculated as:

$$
F=\frac{L . \pi}{C} .100
$$


Table 11. Calibration of the firmness stations for vertical displacement measurement $(\mathrm{mm})$.

\begin{tabular}{|c|c|c|c|c|c|c|c|c|c|}
\hline \multirow{2}{*}{ Parameter } & \multicolumn{3}{|c|}{ BORGWALDT-1 } & \multicolumn{3}{c|}{$\begin{array}{c}\text { BORGWALDT-2 } \\
\text { DD-60A }\end{array}$} & \multicolumn{3}{c|}{$\begin{array}{c}\text { BORGWALDT-3 } \\
\text { DD-60A }\end{array}$} \\
\cline { 2 - 10 } & $\mathrm{E}, \mathrm{F}$ & $\mathrm{C}, \mathrm{D}$ & $\mathrm{A}, \mathrm{B}$ & $\mathrm{E}, \mathrm{F}$ & $\mathrm{C}, \mathrm{D}$ & $\mathrm{A}, \mathrm{B}$ & $\mathrm{E}, \mathrm{F}$ & $\mathrm{C}, \mathrm{D}$ & $\mathrm{A}, \mathrm{B}$ \\
\hline $\bar{d}$ & 4.01 & 6.00 & 8.00 & 4.00 & 6.00 & 7.99 & 4.00 & 6.00 & 7.99 \\
\hline$d$ & 4.00 & 6.00 & 7.99 & 4.00 & 6.00 & 7.99 & 4.00 & 6.00 & 7.99 \\
\hline$u_{e}$ & 0.0014 & 0.0009 & 0.0031 & 0.0014 & 0.0009 & 0.0021 & 0.0026 & 0.0032 & 0.0027 \\
\hline$u_{l}$ & 0.0058 & 0.0058 & 0.0058 & 0.0058 & 0.0058 & 0.0058 & 0.0058 & 0.0058 & 0.0058 \\
\hline$u_{r}$ & 0.0053 & 0.0000 & 0.0032 & 0.0000 & 0.0000 & 0.0000 & 0.0042 & 0.0052 & 0.0032 \\
\hline$u_{F}$ & 0.01 & 0.01 & 0.01 & 0.01 & 0.01 & 0.01 & 0.01 & 0.01 & 0.01 \\
\hline$U_{F}$ & 0.019 & 0.014 & 0.018 & 0.014 & 0.014 & 0.015 & 0.018 & 0.020 & 0.017 \\
\hline
\end{tabular}

The standard uncertainty $\left(u_{F}\right)$ of the measured firmness $(F)$ can be calculated from the measurement of the final dimension $(L)$ of the cigarette and its initial circumference $(C)$, together with the uncertainty of measurement $\left(u_{L}\right)$ and $\left(u_{C}\right)$, respectively. Using Eq. (18) it can be shown in ISO GUM (1995) that:

$$
u_{F}=\sqrt{\left(\frac{\partial F}{\partial L} u_{L}\right)^{2}+\left(\frac{\partial F}{\partial C} \cdot u_{C}\right)^{2}}=\sqrt{\left(F \frac{u_{L}}{L}\right)^{2}+\left(F \frac{u_{C}}{C}\right)^{2}}
$$

Comparison of firmness results at different cigarette moisture contents.

It is possible to compare different products with different moisture contents by estimating the value of the firmness that would be measured by the firmness station if the moisture content were at a reference condition of $13.5 \%$. It is called corrected firmness $\left(F_{c o r}\right)$. Several experiments were performed, and the following empirical conversion expression in Baridó (2002), in Eq. (20), is presently used by a cigarette manufacturer (BAT fit), starting from the measured values of final upright dimension after compression $(\mathrm{L})$, circumference $(\mathrm{C})$ and moisture content $(\mathrm{H})$. However, no information is given about the uncertainty of the correlation and how it can be reduced.

$$
F_{c o r}=100-(100-F) \cdot\left(\frac{13.5}{H}\right)^{1.6}
$$

Influence of the non uniformity of the product on the cigarette firmness measurement.

As seen from Table 11, the firmness station measures the vertical displacement to within \pm 0.021 $\mathrm{mm}$, using reference stainless steel cylinders. When measuring the product firmness, however, due to the fact that the cigarette properties vary, it is necessary to determine an effective value for the firmness uncertainty that takes into account the product non uniformity.
Two samples of 50 cigarettes each for each brand ( $\mathrm{D}$ and $\mathrm{K}$, respectively) were tested in two quality control laboratories (CPD and UDI, respectively). Table 12 shows the average measured values of the final upright dimension after compression $(\bar{L})$, circumference $(\bar{C})$, moisture content $(\bar{H})$ and corrected firmness $\left(\bar{F}_{c o r}\right)$, together with, respectively, their standard deviation $S_{L}, S_{C}$, $S_{H}$ and $s_{c o r}$. It can be seen that due to non uniformity of the product the data dispersion is much larger than its uncertainty of measurement .Therefore, in order to take into account the non uniformity of the product, it was decided to use an effective value of $u_{L}= \pm 0.09 \mathrm{~mm}$ or $\mathrm{U}_{\mathrm{L}}= \pm 0.18 \mathrm{~mm}$ for the effective vertical displacement uncertainty.

Estimating the uncertainty of the corrected firmness measurement

Without considering the uncertainty of the empirical correlation, the uncertainty of estimating the firmness $(\mathrm{u})$ at the reference moisture content of $13.5 \%$ can be estimated according to ISO GUM (1995), using Eq. (20).

$$
\begin{gathered}
c_{L}=\frac{\partial F_{c o r}}{\partial L}=\frac{F}{L} \cdot\left(\frac{13.5}{H}\right)^{1.6} \\
c_{C}=\frac{\partial F_{c o r}}{\partial C}=-\frac{F}{C} \cdot\left(\frac{13.5}{H}\right)^{1.6} \\
c_{H}=\frac{\partial F_{c o r}}{\partial H}=-(100-F) \cdot 1 \cdot 6 \cdot\left(\frac{13.5}{H}\right)^{0.6} \cdot\left(-\frac{13.5}{H^{2}}\right) \\
u_{c o r}=\sqrt{\left(c_{L} \cdot u_{L}\right)^{2}+\left(c_{C} \cdot u_{C}\right)^{2}+\left(c_{H} \cdot u_{H}\right)^{2}}
\end{gathered}
$$


Table 12. Influence of product non uniformity on cigarette corrected firmness measurement.

\begin{tabular}{|c|c|c|c|c|}
\hline \multirow{3}{*}{ LAB } & \multicolumn{4}{|c|}{ Cigarette } \\
\hline & \multicolumn{2}{|c|}{$\mathrm{D}$} & \multicolumn{2}{|c|}{$\mathrm{K}$} \\
\hline & CPD & UDI & CPD & UDI \\
\hline $\bar{L}$ & 5.51 & 5.32 & 5.63 & 5.46 \\
\hline$s_{L}$ & 0.09 & 0.09 & 0.06 & 0.07 \\
\hline $\bar{C}$ & 24.35 & 24.30 & 24.35 & 24.32 \\
\hline$s_{C}$ & 0.08 & 0.08 & 0.05 & 0.06 \\
\hline $\bar{H}$ & 13.72 & 13.37 & 13.48 & 13.05 \\
\hline$s_{H}$ & 0.14 & 0.19 & 0.13 & 0.22 \\
\hline $\bar{F}_{c o r}$ & 71.78 & 68.20 & 72.53 & 68.84 \\
\hline$S_{c o r}$ & 1.12 & 1.19 & 0.88 & 1.38 \\
\hline
\end{tabular}

Estimating the uncertainty of the corrected firmness measurement can be made by using the same average values of $L, C, H$ and $F_{c o r}$ from Table 12. However, to take into account the non uniformity of the product, rather than using their uncertainty of measurement, a maximum value in all situations were used, that is, $u_{L}=0.09 \mathrm{~mm}, u_{C}=0.125 \mathrm{~mm}$ and $u_{H}=0.145 \%$. The combined uncertainty of corrected firmness $\left(u_{c o r}\right)$ can be calculated from Eq. (24).

An analysis of Table 12 and Table 13 shows that the calculated values of the standard uncertainty of the corrected firmness measurement are slightly larger than the standard deviation. The advantage of using this procedure is that there is no need of measuring several times to determine the data dispersion and thus the uncertainty of measurement. Also, it can be concluded from Table 13 that the largest contribution to the corrected firmness uncertainty of measurement is due to vertical displacement measurement, followed by moisture content, and, finally, circumference.

Using Eq. (4) the expanded uncertainty of the corrected firmness measurement $\left(U_{c o r}\right)$ can be estimated in $\pm 2.6\left(U_{c o r}=2 . u_{c o r}, 95.45 \%\right.$ confidence level), without considering the uncertainty of the correlation, Eq. (19), in Baridó (2002).

\section{Validation remarks}

As a first part of this study, it was shown that the cigarette samples to be measured can be stored in a conditioning chamber between 24 to $30 \mathrm{~h}$, so that the tobacco moisture content varies less than $0.2 \%$ over a $3 \mathrm{~h}$ period, meeting in standard ISO 3402 (1999).

As a second part of this study, several experiments were conducted to qualify the presently used methodology for measuring the cigarette firmness as a function of its moisture content (BAT fit), circumference and upright deformation, identifying the sources of errors and estimating the uncertainty of measurement. The calibration of the equipments was important for this analysis. A careful check of the results indicate that the instruments are measuring correctly all the parameters, without the need of corrections. Their uncertainties are low, showing that the differences are due to the properties of the tobacco, which increase the data dispersion. Therefore, a methodology was developed to take them into account, after having analyzed tests with many cigarettes in the cigarette manufacturer quality laboratories. As a result, the effective uncertainty of measurement, with $95.45 \%$ confidence level, was estimated in $\pm 0.25 \mathrm{~mm}$ for circumference, $\pm 0.29 \%$ for moisture content and $\pm 0.18 \mathrm{~mm}$ for vertical displacement measurement in the firmness station.

Table 13. Uncertainty of the corrected firmness measurement $\left(\mathrm{u}_{\mathrm{cor}}\right)$.

\begin{tabular}{|c|c|c|}
\hline \multirow{2}{*}{ LAB } & \multicolumn{2}{|c|}{ Cigarette } \\
\cline { 2 - 3 } & \multicolumn{2}{|c|}{ CPD } \\
\cline { 2 - 3 } & $\mathrm{D}$ & $\mathrm{K}$ \\
\hline $\bar{L}$ & 5.51 & 5.63 \\
\hline$c_{L} \cdot u_{L}$ & 1.13 & 1.16 \\
\hline $\bar{C}$ & 24.35 & 24.35 \\
\hline$c_{C} \cdot u_{C}$ & 0.35 & 0.37 \\
\hline $\bar{H}$ & 13.72 & 13.48 \\
\hline$c_{H} \cdot u_{H}$ & 0.46 & 0.46 \\
\hline $\bar{F}_{c o r}$ & 71.78 & 72.53 \\
\hline$u_{c o r}$ & 1.30 & 1.30 \\
\hline
\end{tabular}

Finally, without considering the uncertainty of the correlation, the uncertainty of the corrected firmness measurement, to reference moisture content of $13.5 \%$, was estimated using the above uncertainties that take into account the tobacco non uniformity. The mean cigarette circumference was found to have the smallest contribution to the corrected firmness uncertainty. The vertical displacement was found to have the largest contribution. The expanded uncertainty of the corrected firmness measurement $\left(U_{F}\right)$ can be estimated in \pm 2.6 , without considering the uncertainty of the correlation, Eq. (19).

As a result of this work, it was found that each type of cigarette must be examined separately because they have different properties. Then the dispersion can be smaller than the one that can be obtained including all of them together.

\section{DEVELOPING A CORRELATION FOR CIGARETTE FIRMNESS}

\section{Introduction}

As seen previously, the cigarette firmness can be measured when a standard force is applied to a sample of ten cigarettes placed horizontally side by side between two parallel plates. The vertical 
displacement of the upper plate is measured, thus defining the final average cigarette upright dimension, which is divided by the cigarette initial diameter, resulting in a measured firmness value. It is possible according to Baridó (2002) to compare different products with different moisture contents by estimating a value that would be measured by the firmness station, called corrected firmness $\left(F_{c o r}\right)$, if the moisture content were at a reference condition of $13.5 \%$, chosen from market observation. According to the same reference, the corrected firmness $\left(F_{c o r}\right)$ is a function of the measured firmness, mean circumference and moisture content.

This section of the paper deals with analyzing different correlations for the corrected firmness $\left(F_{c o r}\right)$, estimating its overall uncertainty due to the curve fit, measured parameters and product non uniformity. Also, in order to reduce the influence of the product non uniformity for estimating its uncertainty of measurement, different cigarette brands were tested.

\section{Methodology}

The following methodology was used for each one of the eleven cigarette brands tested. The whole procedure was repeated six times, supplying enough data for estimating the uncertainty of measurement, including non uniformity of the product.

In order to reduce the influence of the product non uniformity in the uncertainty of measurement, seven sets of fifty cigarettes, each, were selected from different 20 cigarette packages, taken directly from the production. Each one was stored in the conditioning chamber for a twenty four period, at 22 ${ }^{\circ} \mathrm{C}$ and, respectively, 38, 42, 50, 57, 63, 68 and $75 \%$ $\mathrm{RH}$, to give according to Baridó (2002), respectively, cigarette moisture content values of $8,10,12,13.5$, 15,17 and $19 \%$.

For each of the seven moisture content values, forty cigarettes were taken out from the whole set of 50 cigarettes and grouped in four subsets of ten cigarettes, summing up $4 \times 6=24$ samples for firmness measurement, including the repeated runs. Then, half twenty of the amount of the cigarettes used for measuring firmness, summing up 1 × $6=6$ samples, including the repeated runs, were used to measure the moisture content. Finally, twenty cigarettes were selected from the remaining set of $6 \mathrm{x}$ $10=60$ samples, including the repeated runs, for circumference determination.

Using Eq. (2), Eq. (3) and Eq. (4), average values and uncertainty of measurement were determined for the measured firmness, circumference and moisture content.

In order to reduce the uncertainty of measurement, the corrected firmness $(F)$ for each cigarette brand was estimated by least square fitting a polynomial to seven pairs of points, measured firmness versus measured moisture content, and calculating its value and uncertainty at the $13.5 \%$ moisture content reference point.
Several correlations were developed by the least square method and critically analyzed between the corrected firmness, the measured firmness, the measured moisture content and circumference, together with the uncertainty of estimating the corrected firmness with the developed equation, because during the quality control procedure the corrected firmness is not measured, and one has to rely on the correlation.

\section{Sampling}

The methodology described by Baridó (2002) was used to sample the cigarettes for testing each one of the eleven cigarette brands.

For each of the six repeated runs, twenty five packages with twenty cigarettes, each one, were randomly picked up from the production. Two cigarettes were randomly selected from each of the twenty five packages, composing a set of fifty cigarettes. Six more sets were composed the same way, from the same packages, summing up seven sets of fifty cigarettes each one to be used in the tests.

In order to check the influence of the sampling procedure on the results, the same numbers of sets were formed by taking directly the cigarettes from the same packages, until completing fifty cigarettes.

Measurement of firmness and its uncertainty

Following the procedure described previously, six pairs of $\mathrm{L}$ and $\mathrm{C}$ (repeated runs) were measured. The average values and the standard uncertainty were calculated using Eq. (2) and Eq. (3). The measured values of the moisture content were in the $(13.5 \pm$ $0.5) \%$ range. The firmness was calculated using Eq. (18). The standard uncertainty was calculated using Eq. (19).

Table 14 shows the results for eleven cigarette brands. It can be seen that the contribution of the uncertainty of measurement of the final dimension of the cigarette to the uncertainty of firmness measurement is much larger than for circumference measurement also, the firmness value depends on the cigarette brand. And the standard uncertainty is at most $u_{F}=1.6$, which results in $U_{F}=3.2$.

Table 14. Measured firmness at $(13.5 \pm 0.5) \%$.

\begin{tabular}{|c|c|c|c|c|}
\hline Cigarette & $\frac{\partial F}{\partial L} \cdot u_{L}$ & $\frac{\partial F}{\partial C} \cdot u_{C}$ & $\begin{array}{c}\text { Measured } \\
\text { firmness } \\
F\end{array}$ & $\begin{array}{c}\text { Standard } \\
\text { uncert. } \\
u_{F}\end{array}$ \\
\hline A & 1.304 & 0.194 & 74.6 & 1.3 \\
\hline B & 1.265 & 0.265 & 63.4 & 1.3 \\
\hline C & 1.069 & 0.136 & 74.1 & 1.1 \\
\hline D & 1.139 & 0.164 & 74.8 & 1.2 \\
\hline DD & 0.706 & 0.160 & 74.4 & 0.7 \\
\hline E & 1.570 & 0.195 & 74.9 & 1.6 \\
\hline F & 1.001 & 0.233 & 72.0 & 1.0 \\
\hline G & 0.940 & 0.110 & 73.4 & 0.9 \\
\hline H & 1.055 & 0.089 & 72.2 & 1.1 \\
\hline I & 0.967 & 0.230 & 72.9 & 1.0 \\
\hline J & 0.780 & 0.218 & 76.6 & 0.8 \\
\hline
\end{tabular}


Measurement of firmness at $13.5 \%$ moisture content

In principle, the measured firmness of a cigarette at $13.5 \%$ reference condition does not depend on its initial moisture content before entering the conditioning chamber and is called corrected firmness $\left(F_{c o r}\right)$. However, due to uncertainty of the firmness and moisture content measurements, together with the non uniformity of the product, it is necessary smoothing out the data. In this work, this is done by measuring the firmness at seven moisture content values, including the reference one, and six repeated runs (thus, six firmness data points for each moisture content value), fitting a polynomial to the data by the least square method, in Eq. (25) and calculating the firmness value $\left(F_{c o r}\right)$ for $\mathrm{H}=13.5$.

$$
F_{c o r}=a+b . H+c . H^{2}
$$

The standard uncertainty of measurement of the firmness at the reference moisture content value $\left(u_{c o r}\right)$ is given by Eq. (26), according to Orlando (2009), using values for standard uncertainty calculated with the supplied data, in Eq. (2), Eq. (3) and Eq. (4), rather than the maximum ones, given previously:

$$
\begin{gathered}
u_{c o r}=\sqrt{\left(u_{F c o r}\right)^{2}+\left(u_{f i t}\right)^{2}+\left(\frac{\partial F_{c o r}}{\partial H} \cdot u_{H}\right)^{2}} \\
u_{f i t}=\sqrt{\frac{1}{n-3} \cdot \sum_{i=1}^{n}\left[\left(a+b \cdot H_{i}+c \cdot H_{i}^{2}\right)-F_{c o r}\right]^{2}} \\
\frac{\partial F_{c o r}}{\partial H}=b+2 \cdot c \cdot H
\end{gathered}
$$

Where, $u_{F_{c o r}}$ is the standard uncertainty of measurement of firmness at $13.5 \%$ moisture content, by Eq. (19).

$u_{f i t}$ is the standard uncertainty of the fitting.

$u_{H}$ is the standard uncertainty of moisture content.

For analyzing the firmness correlation, the corrected firmness $(13.5 \%)$ was estimated for each cigarette brand using the above methodology. The uncertainty was shown to be slightly larger than the values in Table 14.

Correlation for evaluating the cigarette corrected firmness
In Eq. (20) it is suggested that two normalized parameters can be defined: normalized firmness $(y)$ and normalized moisture content $(X)$

$$
\begin{aligned}
& y=\frac{100-F_{c o r}}{100-F} \\
& x=\frac{13.5}{H}
\end{aligned}
$$

Pairs of data points $x_{i}$ and $y_{i}$ were calculated with the measured values of $F, F_{c o r}$ and $H$. Several functions were chosen for fitting the data points by the least square methods, as indicated by Table 15 .

The data fitting resulted in an expression for the corrected firmness, similar to Eq. (20).

$$
F_{c o r}=100-(100-F) \cdot y(x)
$$

Table 15. Functions for curve fitting the data.

\begin{tabular}{|c|c|}
\hline Function & Equation \\
\hline Power law & $y(x)=x^{n}$ \\
\hline $1^{\text {st }}$ degree polynomial & $y(x)=a+b \cdot x$ \\
\hline $2^{\text {nd }}$ degree polynomial & $y(x)=a+b \cdot x+c . x^{2}$ \\
\hline $3^{\text {rd }}$ degree polynomial & $\begin{array}{c}y(x)=a+b \cdot x+c . x^{2} \\
+d . x^{3}\end{array}$ \\
\hline
\end{tabular}

The root mean square deviation was calculated as the standard uncertainty of the fitting $\left(u_{f i t}\right)$, which could be used to determine the goodness of the fitting and compare different functions.

$u_{f i t}=\sqrt{\frac{1}{m-p} \cdot \sum_{i=1}^{m}\left[100-\left(100-F_{i}\right) \cdot y\left(x_{i}\right)-F_{c o r_{i}}\right]^{2}}$

Where $p$ is the number of constants that should be determined in the fitting, according to the used equation in Table 15. For $\mathrm{H}_{\text {ref }}=13.5$, the standard uncertainty $\left(u_{x}\right)$ of parameter $x$ can be written as:

$$
u_{x}=x \cdot \sqrt{\left(\frac{u_{H_{r e f}}}{H_{r e f}}\right)^{2}+\left(\frac{u_{H}}{H}\right)^{2}}
$$

Using Eq. (31), the standard uncertainty $\left(u_{c o r}\right)$ of the corrected firmness, curve fitted by several equations in Table 15 can be written as in Eq. (34).

$$
u_{c o r}=\sqrt{\left(\frac{\partial F_{c o r}}{\partial x} \cdot u_{x}\right)^{2}+\left(\frac{\partial F_{c o r}}{\partial F} \cdot u_{F}\right)^{2}+u_{f i t}^{2}}
$$


Because of the large number of data points, it is assumed in Eq. (34) that the uncertainty of determining $F_{c o r}$ from the equations in Table 15 is taken into account in the spread of the data for each curve fitting $\left(u_{f i t}\right)$.

\section{Results and analysis}

Comparison between the power law function and the presently used function, (20) and (24).

Using the described methodology, a curve fitting was made using the power law function, in Eq. (31) and Table 15. Its uncertainty was calculated by Eq. (34). Two kinds of fittings were made, using, respectively, the following sets of data points:

- Data points from each cigarette brand, resulting in one fitting for each of the eleven cigarette brands, Table 16.

- Data points from all cigarette brands, resulting in a single fitting, Table 17.

The corrected firmness was then calculated for each cigarette brand and the results compared between the power law and the presently used function (BAT fit), in Eq. (20), together with its uncertainty, calculated according to ISO GUM (1995) by Eq. (24).

Table 16 shows that the maximum firmness difference between the values obtained by Eq. (20) and the power law model is $0.2 \%$, which validates the presently used procedure for estimating the corrected firmness from firmness measurement in Eq. (18) and moisture content measurement at the test conditions.

However, the uncertainty of estimating the corrected firmness for the power law model, in Eq. (34), seems to be a more realistic value than for the present model, in Eq. (24), because it takes into account the influence of the uncertainty of the fitting function on the overall uncertainty of measurement, $u_{\text {fit }}$.

Table 17 shows the influence of the non uniformity of the product on the uncertainty of the corrected firmness measurement. If a single fitting is used for all cigarette brands, rather than using one fitting for each cigarette brand, the uncertainty of the corrected firmness measurement is much larger, although the average value is almost the same (to within $0.2 \%$ ). Thus, it is recommended that one fitting for each cigarette brand be used for analyzing the data.

Influence of the uncertainty of the fitting function on the uncertainty of corrected firmness measurement.

In Eq. (20) it is shown the presently used model for the corrected firmness (BAT fit). In Eq. (24) it is shown the expression to calculate the uncertainty of measurement, according to ISO GUM (1995). The uncertainty of the fitting function $u_{f i t}$ can be calculated using Eq. (32), with $n=1.6$. Thus, combining Eq. (24) and Eq. (34), the overall uncertainty of the corrected firmness can be calculated by:

$$
u_{c o r}=\sqrt{\left(c_{L} \cdot u_{L}\right)^{2}+\left(c_{C} \cdot u_{C}\right)^{2}+\left(c_{H} \cdot u_{H}\right)^{2}+u_{f i t}^{2}}
$$

Table 16. Estimating the corrected firmness with the presently used model (BAT FIT), (20) and (24) and the power law function. Data points from each cigarette brand (eleven fittings).

\begin{tabular}{|c|c|c|c|c|c|c|}
\hline \multirow{2}{*}{$\begin{array}{c}\text { Cigarette } \\
\text { brand }\end{array}$} & \multicolumn{3}{|c|}{ BAT fit: } & \multicolumn{3}{c|}{$\begin{array}{c}\text { Power Law fit: } \\
\text { (20) and (24) }\end{array}$} \\
\cline { 2 - 7 } & $n$ & $\begin{array}{c}F_{\text {cor }} \\
\%\end{array}$ & $\begin{array}{c}U_{\text {cor }} \\
\%\end{array}$ & $n$ & $\begin{array}{c}F_{\text {cor }} \\
\%\end{array}$ & $\begin{array}{c}U_{\text {cor }} \\
\%\end{array}$ \\
\hline A & 1.6 & 74.4 & 3.5 & 1.5 & 74.5 & 5.3 \\
\hline B & 1.6 & 64.3 & 3.4 & 1.3 & 64.1 & 5.0 \\
\hline C & 1.6 & 73.9 & 2.9 & 1.5 & 73.9 & 4.8 \\
\hline D & 1.6 & 73.7 & 3.0 & 1.4 & 73.9 & 5.2 \\
\hline DD & 1.6 & 73.8 & 1.9 & 1.3 & 74.0 & 4.8 \\
\hline E & 1.6 & 74.4 & 4.2 & 1.6 & 74.4 & 6.7 \\
\hline F & 1.6 & 72.0 & 2.7 & 1.4 & 72.0 & 6.2 \\
\hline G & 1.6 & 72.5 & 2.5 & 1.4 & 72.6 & 4.0 \\
\hline H & 1.6 & 72.2 & 2.8 & 1.5 & 72.2 & 5.0 \\
\hline I & 1.6 & 73.1 & 2.6 & 1.4 & 73.1 & 4.1 \\
\hline J & 1.6 & 75.1 & 2.1 & 1.5 & 75.2 & 4.6 \\
\hline
\end{tabular}

Table 17. Comparison between functions. Data points from all cigarette brands (single fitting).

\begin{tabular}{|c|c|c|c|c|c|c|}
\hline \multirow{3}{*}{$\begin{array}{l}\text { Cigarrette } \\
\text { brand }\end{array}$} & \multicolumn{6}{|c|}{ Data points from each cigarrette brand } \\
\hline & \multicolumn{3}{|c|}{$\begin{array}{l}\text { BAR fit: } \\
(20)\end{array}$} & \multicolumn{3}{|c|}{$\begin{array}{c}\text { Power Law: } \\
y=x^{n}\end{array}$} \\
\hline & $n$ & $\begin{array}{c}F_{c o r} \\
\%\end{array}$ & $\begin{array}{c}U_{\text {cor }} \\
\%\end{array}$ & $n$ & $\begin{array}{c}F_{c o r} \\
\%\end{array}$ & $\begin{array}{c}U_{\text {cor }} \\
\%\end{array}$ \\
\hline A & 1.6 & 74.4 & 3.5 & 1.4 & 74.5 & 18.7 \\
\hline $\mathrm{B}$ & 1.6 & 64.3 & 3.4 & 1.4 & 64.2 & 18.7 \\
\hline $\mathrm{C}$ & 1.6 & 73.9 & 2.9 & 1.4 & 73.9 & 18.6 \\
\hline $\mathrm{D}$ & 1.6 & 73.7 & 3.0 & 1.4 & 73.9 & 18.6 \\
\hline DD & 1.6 & 73.8 & 1.9 & 1.4 & 73.9 & 18.5 \\
\hline $\mathrm{E}$ & 1.6 & 74.4 & 4.2 & 1.4 & 74.5 & 18.9 \\
\hline $\mathrm{F}$ & 1.6 & 72.0 & 2.7 & 1.4 & 72.0 & 18.6 \\
\hline $\mathrm{G}$ & 1.6 & 72.5 & 2.5 & 1.4 & 72.7 & 18.5 \\
\hline $\mathrm{H}$ & 1.6 & 72.2 & 2.8 & 1.4 & 72.2 & 18.6 \\
\hline I & 1.6 & 73.1 & 2.6 & 1.4 & 73.1 & 18.6 \\
\hline $\mathrm{J}$ & 1.6 & 75.1 & 2.1 & 1.4 & 75.3 & 18.5 \\
\hline
\end{tabular}

The uncertainty of the corrected firmness using the power law model can be calculated using Eq. (34). Table 18 presents a comparison between the results. It can be clearly seen that the uncertainty of the fitting function must be taken into account for calculating the uncertainty of the corrected firmness.

It is also seen that the uncertainty for the power law is smaller than for the presently used model, which uses a fixed exponent of $n=1.6$. 
Table 18. Influence of the uncertainty of the fitting function on the uncertainty of corrected firmness measurement.

\begin{tabular}{|c|c|c|c|c|c|c|}
\hline \multirow[b]{2}{*}{$\begin{array}{c}\text { Data points from } \\
\text { each cigarette } \\
\text { brand }\end{array}$} & \multicolumn{3}{|c|}{ BAT fit : (20) and (35), $n=1.6$} & \multicolumn{3}{|c|}{ Power law fit $\mathrm{y}=x^{n}$} \\
\hline & $\begin{array}{c}U_{c o r} \\
\text { No } u_{f i t}\end{array}$ & $\begin{array}{c}U_{c o r} \\
\mathrm{w} / u_{f i t} \\
\%\end{array}$ & $\begin{array}{c}U_{c o r} \\
\text { Single fit } \\
\%\end{array}$ & $n$ & $\begin{array}{c}U_{c o r} \\
\mathrm{w} / u_{f i t} \\
\%\end{array}$ & $\begin{array}{c}U_{c o r} \\
\text { single fit } \\
\%\end{array}$ \\
\hline Cigarette brand & $\%$ & & & & & \\
\hline A & 3.5 & 5.7 & 19.5 & 1.5 & 5.3 & 18.7 \\
\hline $\mathrm{B}$ & 3.4 & 11.5 & 19.5 & 1.3 & 5.0 & 18.7 \\
\hline $\mathrm{C}$ & 2.9 & 4.9 & 19.4 & 1.5 & 4.8 & 18.6 \\
\hline $\mathrm{D}$ & 3.0 & 7.4 & 19.5 & 1.4 & 5.2 & 18.6 \\
\hline D D & 1.9 & 8.0 & 19.3 & 1.3 & 4.8 & 18.5 \\
\hline $\mathrm{E}$ & 4.2 & 6.1 & 19.7 & 1.6 & 6.7 & 18.9 \\
\hline $\mathrm{F}$ & 2.7 & 6.7 & 19.4 & 1.4 & 6.2 & 18.6 \\
\hline $\mathrm{G}$ & 2.5 & 5.9 & 19.4 & 1.4 & 4.0 & 18.5 \\
\hline $\mathrm{H}$ & 2.8 & 5.5 & 19.4 & 1.5 & 5.0 & 18.6 \\
\hline I & 2.6 & 5.3 & 19.4 & 1.4 & 4.1 & 18.6 \\
\hline $\mathrm{J}$ & 2.1 & 4.5 & 19.4 & 1.5 & 4.6 & 18.5 \\
\hline
\end{tabular}

Table 19. Influence of the fitting function on the uncertainty of corrected firmness measurement. One fitting for each of the eleven cigarette brand (M) e a single fit (S) for all cigarette brands.

\begin{tabular}{|c|c|c|c|c|c|c|c|c|c|c|c|c|c|}
\hline \multirow{2}{*}{\multicolumn{3}{|c|}{$\begin{array}{c}\text { Cigarette brand } \\
\text { Target }\end{array}$}} & \multicolumn{11}{|c|}{ Least square fit } \\
\hline & & & \multirow[b]{2}{*}{ Type } & \multicolumn{2}{|c|}{ BAT } & \multicolumn{2}{|c|}{ Power Law } & \multicolumn{2}{|c|}{ Linear } & \multicolumn{2}{|c|}{$2^{\text {nd }}$ Degree } & \multicolumn{2}{|c|}{$3^{\text {rd }}$ Degree } \\
\hline Name & $\begin{array}{c}F_{\text {target }} \\
\%\end{array}$ & $\begin{array}{c}U_{t o l} \\
\%\end{array}$ & & $\begin{array}{c}F_{c o r} \\
\%\end{array}$ & $\begin{array}{c}U_{\text {cor }} \\
\%\end{array}$ & $\begin{array}{c}F_{c o r} \\
\%\end{array}$ & $\begin{array}{c}U_{c o} \\
\%\end{array}$ & $\begin{array}{c}F_{c o r} \\
\%\end{array}$ & $\begin{array}{c}U_{c o} \\
\%\end{array}$ & $\begin{array}{c}F_{c o r} \\
\%\end{array}$ & $\begin{array}{c}U_{c o} \\
\%\end{array}$ & $\begin{array}{c}F_{c o r} \\
\%\end{array}$ & $\begin{array}{c}U_{c o} \\
\%\end{array}$ \\
\hline $\mathrm{A}$ & 69.0 & 2.0 & $\mathrm{M}$ & 74.4 & 5.7 & 74.5 & 5.3 & 73.1 & 6.4 & 73.5 & 6.1 & 73.6 & 5.8 \\
\hline $\mathrm{A}$ & 69.0 & 2.0 & $\mathrm{~S}$ & 74.4 & 19.5 & 74.5 & 18.7 & 76.5 & 15.5 & 78.7 & 9.2 & 78.1 & 9.1 \\
\hline $\mathrm{B}$ & 67.0 & 3.0 & $\mathrm{M}$ & 64.3 & 11.5 & 64.1 & 5.0 & 63.7 & 5.1 & 63.2 & 5.7 & 64.3 & 4.3 \\
\hline $\mathrm{B}$ & 67.0 & 3.0 & $\mathrm{~S}$ & 64.3 & 19.5 & 64.2 & 18.8 & 66.8 & 15.5 & 70.1 & 9.3 & 69.4 & 9.2 \\
\hline $\mathrm{C}$ & 72.7 & 2.0 & $\mathrm{M}$ & 73.9 & 4.9 & 73.9 & 4.8 & 72.5 & 5.8 & 72.6 & 6.0 & 73.0 & 3.8 \\
\hline $\mathrm{C}$ & 72.7 & 2.0 & $\mathrm{~S}$ & 73.9 & 19.4 & 73.9 & 18.6 & 76.0 & 15.4 & 78.2 & 9.0 & 77.6 & 9.0 \\
\hline $\mathrm{D}$ & 70.0 & 2.0 & $\mathrm{M}$ & 73.7 & 7.4 & 73.9 & 5.2 & 73.7 & 5.0 & 72.9 & 5.6 & 73.3 & 4.1 \\
\hline $\mathrm{D}$ & 70.0 & 2.0 & $\mathrm{~S}$ & 73.7 & 19.5 & 73.9 & 18.6 & 76.2 & 15.4 & 78.1 & 9.1 & 77.5 & 9.0 \\
\hline DD & 70.0 & 2.0 & $\mathrm{M}$ & 73.8 & 8.0 & 74.0 & 4.8 & 73.8 & 4.6 & 72.9 & 5.2 & 73.4 & 3.4 \\
\hline DD & 70.0 & 2.0 & $\mathrm{~S}$ & 73.8 & 19.3 & 73.9 & 18.5 & 76.1 & 15.3 & 78.2 & 8.9 & 77.6 & 8.9 \\
\hline$E$ & 74.0 & 2.0 & M & 74.4 & 6.1 & 74.4 & 6.7 & 74.6 & 5.5 & 74.2 & 5.3 & 74.2 & 5.3 \\
\hline$E$ & 74.0 & 2.0 & $S$ & 74.4 & 19.7 & 74.5 & 18.9 & 76.6 & 15.7 & 78.7 & 9.5 & 78.1 & 9.5 \\
\hline $\mathrm{F}$ & 73.0 & 2.0 & $\bar{M}$ & 72.0 & 6.7 & 72.0 & 6.2 & 70.1 & 7.5 & 70.6 & 6.9 & 70.9 & 5.0 \\
\hline $\mathrm{F}$ & 73.0 & 2.0 & $\mathrm{~S}$ & 72.0 & 19.4 & 72.0 & 18.6 & 74.2 & 15.4 & 76.6 & 9.1 & 76.0 & 9.0 \\
\hline $\mathrm{G}$ & 70.0 & 2.0 & M & 72.5 & 5.9 & 72.6 & 4.0 & 71.8 & 4.6 & 71.7 & 5.0 & 71.9 & 3.8 \\
\hline $\mathrm{G}$ & 70.0 & 2.0 & $\mathrm{~S}$ & 72.5 & 19.4 & 72.7 & 18.5 & 75.0 & 15.3 & 77.1 & 9.0 & 76.5 & 8.9 \\
\hline $\mathrm{H}$ & 73.0 & 2.0 & $\mathrm{M}$ & 72.2 & 5.5 & 72.2 & 5.0 & 70.8 & 6.0 & 71.0 & 6.1 & 71.4 & 3.9 \\
\hline $\mathrm{H}$ & 73.0 & 2.0 & $\mathrm{~S}$ & 72.2 & 19.4 & 72.2 & 18.6 & 74.4 & 15.3 & 76.8 & 9.0 & 76.2 & 8.9 \\
\hline I & 72.7 & 2.0 & $\mathrm{M}$ & 73.1 & 5.3 & 73.1 & 4.1 & 72.1 & 4.8 & 72.2 & 4.9 & 72.5 & 3.9 \\
\hline I & 72.7 & 2.0 & $\mathrm{~S}$ & 73.1 & 19.4 & 73.1 & 18.6 & 75.2 & 15.3 & 77.5 & 9.0 & 77.0 & 8.9 \\
\hline $\mathrm{J}$ & 72.7 & 2.0 & $\mathrm{M}$ & 75.1 & 4.5 & 75.2 & 4.6 & 74.5 & 4.7 & 74.4 & 5.2 & 74.5 & 5.1 \\
\hline $\mathrm{J}$ & 72.7 & 2.0 & $\mathrm{~S}$ & 75.1 & 19.4 & 75.3 & 18.5 & 77.6 & 15.3 & 79.4 & 8.9 & 78.7 & 8.8 \\
\hline
\end{tabular}

Finally, if a smaller uncertainty is required, one fitting for each of the eleven cigarette brands must be used.

Influence of the fitting function on the uncertainty of corrected firmness measurement.

Using the described methodology, a curve fitting was made using equations of Table 15. Its uncertainty was calculated by Eq. (34). Two kinds of fittings were made, using, respectively, the following sets of data points:

- Data points from each cigarette brand, resulting in one fitting for each of the eleven cigarette brands, Table 19. 
Table 20. Probability (Prob) of the cigarette corrected firmness be in the range $\left(F_{\text {target }} \pm U_{\text {tol }}\right)$ defined by the target value $\left(F_{\text {target }}\right)$ and its tolerance $\left(U_{\text {tol }}\right)$.

\begin{tabular}{|c|c|c|c|c|c|c|c|c|c|c|c|c|c|}
\hline \multirow{2}{*}{\multicolumn{3}{|c|}{$\frac{\text { Cigarette brand }}{\text { Target }}$}} & \multicolumn{11}{|c|}{ Least square fit } \\
\hline & & & \multirow[b]{2}{*}{ Type } & \multicolumn{2}{|c|}{ BAT } & \multicolumn{2}{|c|}{ Power Law } & \multicolumn{2}{|c|}{ Linear } & \multicolumn{2}{|c|}{$2^{\text {nd }}$ Degree } & \multicolumn{2}{|c|}{$3^{\text {rd }}$ Degree } \\
\hline Name & $\begin{array}{c}F_{\text {target }} \\
\%\end{array}$ & $\begin{array}{l}U_{\text {tol }} \\
\%\end{array}$ & & $\begin{array}{c}F_{c o r} \\
\%\end{array}$ & $\begin{array}{c}\text { Prob } \\
\%\end{array}$ & $\begin{array}{c}F_{\text {cor }} \\
\%\end{array}$ & $\begin{array}{c}\text { Prob } \\
\%\end{array}$ & $\begin{array}{c}F_{\text {cor }} \\
\%\end{array}$ & $\begin{array}{c}\text { Prob } \\
\%\end{array}$ & $\begin{array}{c}F_{\text {cor }} \\
\%\end{array}$ & $\begin{array}{c}\text { Prob } \\
\%\end{array}$ & $\begin{array}{c}F_{\text {cor }} \\
\%\end{array}$ & $\begin{array}{c}\text { Prob } \\
\%\end{array}$ \\
\hline A & 69.0 & 2.0 & M & 74.4 & 11.2 & 74.5 & 9.1 & 73.1 & 22.8 & 73.5 & 19.0 & 73.6 & 17.4 \\
\hline $\mathrm{A}$ & 69.0 & 2.0 & $\mathrm{~S}$ & 74.4 & 14.0 & 74.5 & 14.3 & 76.5 & 12.9 & 78.7 & 4.2 & 78.1 & 5.2 \\
\hline $\mathrm{B}$ & 67.0 & 3.0 & $\bar{M}$ & 64.3 & 36.0 & 64.1 & 50.7 & 63.7 & 44.6 & 63.2 & 38.1 & 64.3 & 55.1 \\
\hline $\mathrm{B}$ & 67.0 & 3.0 & $\mathrm{~S}$ & 64.3 & 23.3 & 64.2 & 24.0 & 66.8 & 30.1 & 70.1 & 39.7 & 69.4 & 43.2 \\
\hline $\mathrm{C}$ & & 2.0 & $\bar{M}$ & 73.9 & 53.2 & 73.9 & 53.9 & 72.5 & 50.9 & 72.6 & 49.5 & 73.0 & 70.1 \\
\hline $\mathrm{C}$ & .7 & 2.0 & $\bar{S}$ & 73.9 & 16.2 & 73.9 & 16.9 & 76.0 & 18.7 & 78.2 & 17.1 & 77.6 & 19.7 \\
\hline $\bar{D}$ & 70.0 & 2.0 & $\bar{M}$ & 73.7 & 26.1 & 73.9 & 22.1 & 73.7 & 23.7 & 72.9 & 33.4 & 73.3 & 25.8 \\
\hline $\mathrm{D}$ & 70.0 & 2.0 & $\bar{S}$ & 73.7 & 15.1 & 73.9 & 15.6 & 76.2 & 14.9 & 78.1 & 7.7 & 77.5 & 9.3 \\
\hline DD & .0 & 2.0 & M & 73.8 & 25.3 & 74.0 & 19.6 & 73.8 & 21.1 & 72.9 & 33.5 & 73.4 & 20.4 \\
\hline DD & 70.0 & 2 & -5 & 73.8 & 15.2 & 73.9 & 15.7 & 76.1 & 15.1 & 78.2 & 7.1 & 77.6 & 8.9 \\
\hline$E$ & $\overline{4.0}$ & 2.0 & $\bar{M}$ & 74.4 & 48.4 & 74.4 & 44.7 & 74. & 52.2 & 74.2 & 54.8 & 74.2 & 54.8 \\
\hline $\mathrm{E}$ & 4.0 & 2.0 & 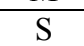 & 74.4 & 16.1 & 74.5 & 16.7 & 76.6 & 19.1 & 78.7 & 20.6 & 78.1 & 23.0 \\
\hline $\mathrm{F}$ & 73.0 & 2.0 & M & 72.0 & 43.2 & 72.0 & 46.0 & 70.1 & 31.0 & 70.6 & 35.3 & 70.9 & 43.4 \\
\hline $\mathrm{F}$ & 3.0 & 2.0 & $\mathrm{~S}$ & 72.0 & 16.3 & 72.0 & 16.9 & 74.2 & 20.3 & 76.6 & 25.3 & 76.0 & 27.9 \\
\hline $\mathrm{G}$ & .0 & 2.0 & $\mathrm{M}$ & 72.5 & 36.9 & 72.6 & 37.1 & 71.8 & 48.5 & 71.7 & 47.8 & 71.9 & 50.1 \\
\hline G & & 2.0 & $\mathrm{~S}$ & 72.5 & 15.8 & 72.7 & 16.4 & 75.0 & 16.7 & 77.1 & 10.7 & 76.5 & 12.8 \\
\hline $\mathrm{H}$ & 73.0 & 2.0 & $\mathrm{M}$ & 72.2 & 51.4 & 72.2 & 55.3 & 70.8 & 39.3 & 71.0 & 40.5 & 71.4 & 54.9 \\
\hline $\mathrm{H}$ & 73.0 & 2.0 & $\bar{S}$ & 72.2 & 16.3 & 72.2 & 17.0 & 74.4 & 20.3 & 76.8 & 24.6 & 76.2 & 27.2 \\
\hline I & 72.7 & 2.0 & $\bar{M}$ & 73.1 & 54.4 & 73.1 & 66.2 & 72.1 & 58.1 & 72.2 & 57.6 & 72.5 & 69.2 \\
\hline I & 72.7 & 2.0 & $\bar{S}$ & 73.1 & 16.3 & 73.1 & 17.0 & 75.2 & 19.6 & 77.5 & 20.2 & 77.0 & 22.4 \\
\hline $\mathrm{J}$ & 72.7 & 2.0 & $\mathrm{M}$ & 75.1 & 40.4 & 75.2 & 38.9 & 74.5 & 48.1 & 74.4 & 46.9 & 74.5 & 46.3 \\
\hline $\mathrm{J}$ & 72.7 & 2.0 & $\mathrm{~S}$ & 75.1 & 15.8 & 75.3 & 16.5 & 77.6 & 16.9 & 79.4 & 12.0 & 78.7 & 14.7 \\
\hline
\end{tabular}

Table 21. Influence of the sampling procedure on the uncertainty of the corrected firmness.

\begin{tabular}{|c|c|c|c|c|c|c|c|c|c|c|c|c|c|}
\hline \multirow{2}{*}{\multicolumn{3}{|c|}{$\begin{array}{c}\text { Cigarette brand } \\
\text { Target }\end{array}$}} & \multicolumn{11}{|c|}{ Least square fit } \\
\hline & & & \multirow[b]{2}{*}{ Type } & \multicolumn{2}{|c|}{ BAT } & \multicolumn{2}{|c|}{ Power Law } & \multicolumn{2}{|c|}{ Linear } & \multicolumn{2}{|c|}{$2^{\text {nd }}$ Degree } & \multicolumn{2}{|c|}{$3^{\text {rd }}$ Degree } \\
\hline Name & $\begin{array}{c}F_{\text {target }} \\
\%\end{array}$ & $\begin{array}{c}U_{t o l} \\
\%\end{array}$ & & $\begin{array}{c}F_{\text {cor }} \\
\%\end{array}$ & $\begin{array}{l}U_{c o} \\
\%\end{array}$ & $\begin{array}{c}F_{c o r} \\
\%\end{array}$ & $\begin{array}{l}U_{c o} \\
\%\end{array}$ & $\begin{array}{c}F_{\text {cor }} \\
\%\end{array}$ & $\begin{array}{l}U_{c o} \\
\%\end{array}$ & $\begin{array}{c}F_{\text {cor }} \\
\%\end{array}$ & $\begin{array}{l}U_{c o} \\
\%\end{array}$ & $\begin{array}{c}F_{\text {cor }} \\
\%\end{array}$ & $\begin{array}{l}U_{c o} \\
\%\end{array}$ \\
\hline $\mathrm{D}$ & 70.0 & 2.0 & $\bar{M}$ & 73.7 & 26.1 & 73.9 & 5.2 & 73.7 & 5.0 & 72.9 & 5.6 & 73.3 & 4.1 \\
\hline $\mathrm{D}$ & 70.0 & 2.0 & $\bar{S}$ & 73.7 & 15.1 & 73.9 & 18.6 & 76.2 & 15.4 & 78.1 & 9.1 & 77.5 & 9.0 \\
\hline $\mathrm{DD}$ & 70.0 & 2.0 & $\mathrm{M}$ & 73.8 & 25.3 & 74.0 & 4.8 & 73.8 & 4.6 & 72.9 & 5.2 & 73.4 & 3.4 \\
\hline $\mathrm{DD}$ & 70.0 & 2.0 & $\bar{S}$ & 73.8 & 15.2 & 73.9 & 18.5 & 76.1 & 15.3 & 78.2 & 8.9 & 77.6 & 8.9 \\
\hline
\end{tabular}

- Data points from all cigarette brands, resulting in a single fitting, Table 19.

It can be seen from Table 19 that for reducing the uncertainty of the corrected firmness, one fitting for each of the eleven cigarette brand should be used, rather than a single fitting for all cigarette brands.

The power law function is slightly better than the presently used fit (BAT fit) because it determines the exponent of the equation, rather than considering a fixed value of $n=1.6$.

It was also observed that in many cases a reduction of the uncertainty of the corrected firmness could be obtained by fitting a $2^{\text {nd }}$ or $3^{\text {rd }}$ degree polynomial to the experimental data. This is also true when using a single fit for all cigarette brands.

The choice of the target and tolerance for product acceptance in a quality control procedure.

For product acceptance in a quality control procedure a target value $\left(F_{\text {target }}\right)$ and its tolerance $\left(U_{t o l}\right)$ was chosen and indicated in Table 20.
For a given cigarette brand with average corrected firmness value $\left(F_{c o r}\right)$ and uncertainty $\left(U_{c o r}\right)$, to within $95.45 \%$, the probability of the estimated corrected firmness be in the $\left(F_{\text {target }} \pm U_{\text {tol }}\right)$ range can be calculated assuming a normal probability distribution, and indicated in Table 20. In principle, the least square fit that results in the largest probability value should be chosen. This procedure takes into account the fact that the corrected firmness and its uncertainty vary with the fitting function.

It can be seen that one fit for each of the eleven cigarette brand should be preferred over a single fit for all cigarette brands. Also, the power law fit gives slightly better results than the presently used fit (BAT fit). Finally, better results can be obtained with a $2^{\text {nd }}$ and $3^{\text {rd }}$ degree polynomial fit.

It is clearly seen that the target value and its tolerance should be redefined, so that the characteristics of the tobacco be taken into account more efficiently in the acceptance procedure. Ideally, 
both corrected firmness and uncertainty should coincide, respectively, with target and tolerance.

Influence of the sampling procedure on the uncertainty of the corrected firmness.

In order to check the influence of the sampling procedure on the results, the same numbers of sets were formed by taking directly the cigarettes from the same packages, until completing fifty cigarettes. Two types of cigarette brands were chosen: D and DD.

Table 21 presents the results. It can be seen that the calculated corrected firmness is almost the same for both sampling procedures. The difference is at most $0.1 \%$. The uncertainty is approximately the same.

Thus, it can be concluded that the sampling procedure did not influence the results.

\section{CONCLUSIONS}

As a first part of this study, it was shown that the cigarette samples to be measured can be stored in a conditioning chamber between 24 to $30 \mathrm{~h}$, so that the tobacco moisture content varies less than $0.2 \%$ over a $3 \mathrm{~h}$ period, meeting in standard ISO 3402 (1999).

As a second part of this study, several experiments were conducted to qualify the presently used methodology for measuring the cigarette firmness as a function of its moisture content and circumference, identifying the sources of errors and estimating the uncertainty of measurement. The calibration of the equipments was important for this analysis. A careful check of the results indicate that the instruments are measuring correctly all the parameters, without the need of corrections. Their uncertainties are low, showing that the differences are due to the properties of the tobacco, which increase the data dispersion. Therefore, a methodology was developed to take them into account, after having analyzed tests with many cigarettes in two manufacturer quality laboratories. As a result, the effective uncertainty of measurement, with $95.45 \%$ confidence level, was estimated in $\pm 0.25 \mathrm{~mm}$ for circumference, $\pm 0.29 \%$ for moisture content and \pm $0.18 \mathrm{~mm}$ for vertical displacement measurement in the firmness station.

A methodology was developed to determine the uncertainty of the corrected firmness measurement to reference moisture content of $13.5 \%$, using the above uncertainties that take into account the tobacco non uniformity. The mean cigarette circumference was found to have the smallest contribution to the corrected firmness uncertainty. The vertical displacement was found to have the largest contribution. The expanded uncertainty of the corrected firmness measurement $(U)$ can be estimated in \pm 2.6 , without considering the uncertainty of the correlation in Eq. (19).

As a result of this work, it was found that each type of cigarette must be examined separately because they have different properties. Then the dispersion can be smaller than the one that can be obtained including all of them together.

A methodology was developed to estimate the corrected firmness (at 13.5\% moisture content) from firmness and moisture content measurements at the test conditions.

The tests described in this paper used eleven types of cigarettes and the firmness was measured by the previously qualified procedures used by the cigarette manufacturer. The influence of the sampling procedure for choosing the cigarettes was found to be very small. The method of minimum squares was used in the development of correlations jointly with uncertainty estimate, for power law, linear, $2^{\text {nd }}$ degree polynomial and $3^{\text {rd }}$ degree polynomial fits, and comparing with the presently used fit (BAT fit). The influence of the fitting function on the uncertainty of corrected firmness measurement was analyzed and considered important.

The influence of the tobacco non homogeneity on the uncertainty of corrected firmness measurement was examined and concluded that if a smaller uncertainty is required one fit for each of the eleven cigarette brand tested should be used, rather than a single fit for all cigarette brands.

A comparison was made between the different fits. The power law function was found to be slightly better than the presently used fit (BAT fit) because it determines the exponent of the equation, rather than considering a fixed value of $n=1.6$. It was also observed that in many cases a reduction of the uncertainty of the corrected firmness could be obtained by fitting a $2^{\text {nd }}$ or $3^{\text {rd }}$ degree polynomial to the experimental data. This is also true when using a single fit for all cigarette brands.

For product acceptance in a quality control procedure a target value and its tolerance are chosen, defining a range for cigarette acceptance. For a given cigarette brand with average corrected firmness value and uncertainty, the probability of the estimated corrected firmness to be in the defined range was calculated assuming a normal probability distribution, and found to be much less than $100 \%$. This means that the target value and its tolerance must be redefined. Ideally, the target value and its tolerance should coincide, respectively, with the average value of the estimated corrected firmness and its uncertainty, to within a given confidence level.

Finally, the choice of the fitting function is suggested to be made by maximizing the probability of an estimated corrected firmness to be in the interval defined by the target value and its tolerance. This procedure takes into account the fact that the corrected firmness and its uncertainty vary with the fitting function. 


\section{ACKNOWLEDGEMENTS}

The authors are indebted to Souza Cruz for having provided all the support for making the experiments.

\section{REFERENCES}

Baridó, M., 2002, Avaliação do modelo matemático de correção na determinação de firmeza do cigarro - Janeiro 2002, Relatório $\mathrm{N}^{\circ}$ T.209.2002.27.02.2002, Souza Cruz. (in Portuguese)

ISO 3402, 1999, Tobacco and tobacco products, International Organization for Standardization, Switzerland.

ISO GUM, 1995, Guide to the expression of uncertainty of measurement, International Organization for Standardization, Switzerland.

Nogueira, F. G., 2005, Padronização e confiabilidade metrológica dos resultados de firmeza de cigarro, Master Dissertation, PUC-Rio.

Orlando, A. F., 2009, Uncertainty analysis in experimental mechanics, in Experimental Mechanics, [Ed. José Luiz de França Freire], in Encyclopedia of Life Support Systems (EOLSS), Developed under the auspices of the UNESCO, Eolss Publishers, Oxford, UK, [http://www.eolss.net].

Received: October 10, 2009

Revised: November 10, 2009

Accepted: December 10, 2009 